\title{
Why do Europeans Work Less than Americans? Public Consumption and Welfare Benefits as a Cause of the North-Atlantic Divide
}

\author{
Axel Hall \\ Gylfi Zoega
}

CESIFO WORKING PAPER NO. 5264

CATEGORY 4: LABOUR MARKETS

MARCH 2015

An electronic version of the paper may be downloaded

- from the SSRN website:

- from the RePEc website:

wWw.SSRN.com

Www.RePEc.org

- from the CESifo website:

www.CESifo-group.org/wp 


\title{
Why do Europeans Work Less than Americans? Public Consumption and Welfare Benefits as a Cause of the North-Atlantic Divide
}

\begin{abstract}
We propose an explanation of why Europeans choose to work fewer hours than Americans and also suffer higher rates of unemployment. Labor market regulations, unemployment benefits, and high levels of public consumption in many European countries reduce, ceteris paribus, the gains from being employed, which makes employed workers ask for higher wages relative to productivity. The higher wages make firms offer fewer vacancies, as well as raising the opportunity cost of working by enabling employed workers to enjoy time-consuming consumption activities. We find empirical support for our thesis.
\end{abstract}

JEL-Code: J630, J640, J650.

Keywords: job search, unemployment, working hours.

Axel Hall

Reykjavik University

School of Business

Ofanleiti 2

Iceland - 103 Reykjavik

axelhall@ru.is
Gylfi Zoega

University of Iceland

Department of Economics

Saemundargata 2

Iceland - 101 Reykjavik

gz@hi.is

March 11, 2015

The authors thank seminar participants at CES, Munich, in January 2015 for their comments. 


\section{Introduction}

Many European countries have both short work weeks and high rates of unemployment. Spain, Belgium, France, Italy, and Portugal have fewer hours of work per employed worker than better-performing countries such as the UK, Australia, and the US, as well as higher rates of unemployment. ${ }^{1}$ In most cases, attempts to explain the two observations - high unemployment, on the one hand, and fewer hours of work among employed workers, on the other — have addressed each separately and not found a unified explanation for both.

We present an explanation for both observations based on the insight that paying people for being idle has the effect of both reducing employment and reducing the hours worked by the employed. The insight for our result can be traced to Becker (1965), who made consumption require time off from work. For example, it takes time to go to the theater, travel, and listen to music. In fact, it could be said that all consumption requires time but that the amount of time differs between one consumption activity and another. For this reason, increased wage income can be expected to increase the demand for both consumption and leisure. According to our thesis, any factor - such as unions, unemployment benefits, or other welfare payments - that has the effect of increasing wages relative to productivity will raise the opportunity cost of working by increasing the level of consumption while reducing the profits from posting vacancies due to higher wages and fewer hours of work, thus providing a unified explanation for a shorter work week and higher unemployment. As a result, hourly productivity will also be higher, assuming diminishing returns to hours worked for each worker, an effect that has been recognized since at least the work of Alfred Marshall. ${ }^{2}$

Numerous authors have attempted to explain why hours worked per capita in the United States and Europe have diverged in recent decades. The number of hours was about the same in the early 1970s but has now fallen significantly behind in many, although not all, European

\footnotetext{
${ }^{1}$ Average weekly hours for full-time dependent employees in year 2012 among the more developed OECD countries range from 42.8 in Australia, 42.7 in New Zealand, 42.4 in the UK, and 41.8 in the US to 39.4 in both France and Italy and 40.1 in Spain. The corresponding unemployment rates in 2012 were 5.2\% in Australia, 6.9\% in New Zealand, 7.9\% for the UK, and 8.1\% for the US, as opposed to 9.3\%, 10.8\%, and 24.9\% in France, Italy, and Spain, respectively.

${ }^{2}$ According to Marshall (1890), "When the hours, the nature of the work done, the physical conditions under which it is done ... are such as to cause great wear-and-tear of body or mind or both ... then... a case a moderate diminution of the hours of labor would diminish the national dividend only temporarily: for as soon as the improved standard of life had had time to exert its full effect on the efficiency of the workers, their increased energy, intelligence and force of character would enable them to do as much as before in less time (p. 694).”
} 
countries. ${ }^{3}$ According to Alesina, Glaeser, and Sacerdote (2006) roughly one quarter of the total difference in weekly hours per capita between the United States, on the one hand, and France, Germany, and Italy, on the other hand, is explained by differences in working hours during a normal week, whereas the remaining three quarters is explained by a lower number of weeks worked - that is, vacation time - and the employment rate. For France and Germany, the difference in vacation time is the more important of the two factors, while in the case of Italy it is the employment rate. Interestingly, the United States has only 3.9 weeks of holiday and vacations, while Italy and Germany have 7.9 and 7.8 weeks, respectively, and France 7.0 weeks.

We start with the rather straightforward explanation of Blanchard (2004), who argued that Europeans have different preferences towards leisure, which makes them enjoy to a greater extent the rewards of higher productivity in the form of leisure rather than increased consumption. He suggested that if a European economy is hit by an adverse aggregate shock, unions and a left-leaning government will attempt to maintain unchanged employment by reducing the number of hours worked. The rather obvious problem with this explanation is that it does not address the sources of the differences in preference, nor is it consistent with the fact that Europeans worked more hours in the 1960s.

Prescott (2004) attributed the differences in labor supply between Europe and the United States to differences in tax rates, which were smaller in the 1970s than they are currently. But the estimated elasticities of labor supply at the microeconomic level are too small for tax changes to explain the fall in labor supply in Europe. Glasear, Sacerdote, and Scheinkman (2003) propose an explanation for the discrepancy between the estimated labor supply elasticities at the microeconomic level and the ones required for changes in taxes to have the observed effect on labor supply. Here, positive externalities in leisure and production make it more desirable to enjoy leisure when others are doing so and more productive to work when others are also at work. This generates what they call a social multiplier, which makes the estimated elasticities at the macroeconomic level larger than the ones estimated at the microeconomic level.

There is also the paper by Bell and Freeman (2001), who argue that Americans work more than Europeans not because they pay lower taxes but because they have a greater incentive to work hard in the hope of future rewards, as income distribution is more unequal in the United

\footnotetext{
3 The Nordic countries of Denmark, Finland, Iceland, Norway, and Sweden are an exception. See Hall and Zoega (2014).
} 
States than in Europe. In a cross-section of occupations, these authors find that hours worked are positively correlated with earnings inequality.

Alesina, Glaeser, and Sacerdote (2006) propose an alternative explanation for the differences in hours worked between Europe and the United States. According to their thesis, unionization and labor market regulations are correlated across countries with both taxes and hours of work. Both factors increased in Europe in the 1970s and 1980s. The argument is similar to that of Blanchard (2004), in that unions in Europe pursued a policy of work-sharing by asking for a reduction in hours worked as a response to rising unemployment in declining industries. A case in point is the 35-hour work week implemented in France in 2000.

As it turns out, these factors have also been mentioned, in a separate literature, as causes of high unemployment. Layard, Nickell, and Jackman (1991, 2005) and Nickell et al. (2005) report a correlation between unemployment, on the one hand, and labor union coverage, labor union centralization, the unemployment benefit replacement ratio, the duration of benefits, and active labor market policies, on the other. In their model, differences in these institutions explain differences in mean unemployment across countries, and changes in these institutions can explain changes in unemployment over time within a given country. In contrast, Phelps (1994), Fitoussi, Jestaz, Hoon, and Phelps (1997) and Phelps and Zoega (2001) explain changes in mean unemployment in terms of macroeconomic variables, such as the rate of growth of productivity and the world real rate of interest, the level of private and social wealth, and the world real price of oil. Here the effect of the macroeconomic factors on unemployment depends on the same labor market institutions. Thus labor unions and unemployment benefits affect the slope of the wage curve in the labor market, which determines the effect of shifts in labor demand on equilibrium unemployment. A paper using the same approach is that of Blanchard and Wolfers (2000).

Rogerson (2006) documents the differences in hours of work across OECD countries and argues that technology and taxes can explain changes between the 1950s and early 2000s. Pissarides (2007) derives a matching model of the labor market and shows how the strong productivity growth in the 1960s (associated with catching up with the United States) caused European unemployment to be low, while the growth slowdown in the following decades made it rise and exceed the rate of unemployment in the US. Pissarides finds that taxes may explain part of the fall in hours of work in Europe, since taxes make home production more attractive at the expense of service employment. Ngai and Pissarides (2008) study the relationship between market production and home production over long periods of time and explain changes in the two by uneven TFP growth in market and home production. 
In our model, we show how Becker's insight on time required for consumption can explain why unions, unemployment benefits, and public consumption can account for both a lower number of hours of work and a higher unemployment rate in European countries. The model explains why Europeans may desire more hours of leisure than Americans, since shorter working hours in Europe cannot be explained by more time spent on home production, as is pointed out by Alesina et al. (2006). We introduce Becker's intuition into a matching model of the Pissarides (2000) variety, ${ }^{4}$ where workers and firms bargain over both wages and hours of work to show how a generous welfare system that supports the unemployed will raise wages relative to productivity, reduce employment, and shorten the length of the work week negotiated in employment contracts.

\section{Model setup}

The representative worker can either be employed, with hours worked $h>0$, or unemployed, with $h=0$. This means that consumption will either be

$$
c_{t}=(1-\tau) w_{t} h_{t}+\bar{c}
$$

or

$$
c_{t}=(1-\tau) z_{t}+\bar{C}
$$

where $\tau$ is the tax rate on labor income and benefits, $w_{t}$ is the real wage, $h_{t}$ denotes hours worked, $z_{t}$ stands for unemployment benefits, and $\bar{c}$ is public consumption. In this way, we make private and public consumption be perfect substitutes, as, for example, private and public education and healthcare or private and public parks. ${ }^{5}$ Furthermore, we assume that taxes are collected from employees and that there are no taxes on employers.

We assume the following functional form for the utility function

$$
u(c, h)=c \cdot \phi(1-h), \phi(1)=1, \phi^{\prime}>0, \phi^{\prime \prime}<0 .
$$

The function is linear in consumption and has the property that the substitution and income effects of wage changes cancel out in the absence of bargaining. The utility function assumes that the utility of consumption depends on the time available from work, incorporating the

\footnotetext{
${ }^{4}$ See also Pissarides (1985), Mortensen and Pissarides (1994) and Cahuc and Zylberberg (2004).

${ }^{5}$ Scitovsky (1951) and later Winston (1965) argued that public consumption had an effect on employment. Zoega (1997) derived the effect of higher public consumption, financed by a proportional tax on wage income, on unemployment in an efficiency wage model of the shirking variety. In his model, a higher level of public consumption benefits the unemployed more than the employed due to diminishing marginal utility of consumption, which forces firms to raise wages for incentive reasons with the effect of lowering employment.
} 
insights of Becker (1965). The fewer are the hours of work, the greater is the utility of a given level of consumption. Our results will all come back to this intuition.

The matching function is assumed to be increasing in both the number of vacancies and the number of unemployed workers, concave, and homogeneous of degree one. We write the matching function as a function of labor market tightness $\theta$, defined as the ratio of vacancies to unemployment. The rate at which vacant jobs become filled (exit rate from vacancy) then becomes $m(\theta)=M\left(\theta^{-1}, 1\right)$. From the properties of the matching technology, the derivative with respect to $\theta$ is negative. The elasticity of $m$ is non-positive with an absolute value equal to $\eta(\theta)$. The probability that an unemployed worker will get a job is $\theta \cdot m(\theta)$. It can be shown that the elasticity of $\theta m(\theta)$ is $1-\eta(\theta)$. Finally, we denote the job destruction rate by $q$.

We let $U$ and $E$ represent the discounted value of the expected utility stream of an unemployed and an employed worker, respectively. With a perfect capital market, interest rate $r$, and infinite horizons, $E$ satisfies the Bellman equation

$$
r E=u(c, h)+q \cdot(U-E)
$$

where $r E$ is the required return from having a filled job where consumption is given by equation (1). The probability of the change of state from being unemployed to becoming employed can be described by a Poisson process with rate $\theta m(\theta)$. $U$ satisfies the Bellman equation

$$
r U=u(c, 0)+\theta \cdot m(\theta) \cdot(E-U)
$$

where consumption is given by equation (2) and $r U$ is the required return from being unemployed. Let $J$ be the present discounted value of expected profits from a filled job and $V$ the present discounted value of expected profits from a vacant job. The vacant job costs $a$ per unit of time ( $a$ for advertising a job!) and is filled according to a Poisson process with rate $m(\theta) . V$ thus satisfies:

$$
r V=-a+m(\theta) \cdot(J-V)
$$

In the same manner, the asset value of an occupied job $J$ satisfies a value equation where the required return is $r J$. A filled job yields an instantaneous net return $f(h)$ - wh, where $f(h)$ is a strictly concave production function in hours worked. The job changes state with a probability q; hence $J$ satisfies:

$$
r J=f(h)-w h+q \cdot(V-J)
$$


The total surplus $S$ for firms and workers can be written as

$$
S=(J-V)+(E-U)
$$

where, from equations (4) and (5), we find that

$$
E-U=\frac{u(c, h)-u(z(1-\tau), 0)}{r+q+m(\theta) \theta} .
$$

We use the model to show how the government can reduce employment and hours of work by paying people for doing nothing. The payment takes the form of non-wage income, which consists of benefits paid to the unemployed $z$ and the provision of public consumption that gives each individual a level of consumption $\bar{c}$, independent of employment status.

The government's budget constraint is as follows, where the unemployment rate is denoted by $\tilde{u}, b$ is public debt, and $\dot{b}$ is the budget deficit written as the time derivative of public debt:

$$
\tilde{u} \cdot z+\bar{c}+r b=(w h \tau) \cdot(1-\tilde{u})+(z \tau) \cdot \tilde{u}+\dot{b}
$$

The left-hand side of the equation has the expenditures on unemployment benefits, public consumption per capita, and interest payments per capita, while the right-hand side has tax revenues, collected through a proportional tax on wage income and unemployment benefits, and the budget deficit. The model will show how an increase in taxes $\tau$ used to finance either an increase in benefits $z$ or public consumption $\bar{C}$ will have the effect of reducing both employment and the number of hours of work $h$, in addition to raising hourly productivity.

\section{Market equilibrium}

Our model solution consists of three equations in three endogenous variables. The first equation shows the supply of vacancies given the assumption of free entry. The second equation is the contract curve, which gives all combinations of wages and hours of work in a Nash equilibrium. The third equation is a wage curve that sets wages as a function of productivity, labor market tightness, and non-wage income.

\subsection{Labor demand}

New jobs will be created as long as the profits from a vacant job remain strictly positive; i.e., $V>0$ due to the free entry condition $V=0$. This determines the demand for labor using equations (6) and (7), 


$$
\frac{f(h)-w h}{r+q}=\frac{a}{m(\theta)}
$$

where $f(h)$ is the production function with a positive first derivative and a negative second derivative. The left-hand side of the equation denotes the present discounted value of profits from an employed worker - this is the marginal benefit from creating a vacancy - and the right-hand side is the expected cost of a vacancy. Firms will create new vacancies until this condition is satisfied.

\subsection{The contract curve}

Consider the situation of a worker and a firm that have met and have an opportunity to produce a flow of output $f(h)$, which is a function of hours worked and pays wages per hour worked $w$. The worker and his employer bargain over both the level of wages $w$ and the number of hours $h$. This translates into finding the maximum of the following expression for the sharing of the surplus between workers and firms. This represents a generalized Nash bargaining solution, where $\gamma$ denotes the bargaining power of the worker:

$$
\underset{w, h}{\operatorname{Max}}(J(w, h)-V)^{1-\gamma}(E(w, h)-U)^{\gamma} .
$$

The first-order conditions can be made more manageable by taking the logarithm of the objective function, which defines the optimum:

$$
\begin{aligned}
& \left(\frac{\gamma}{E-U}\right) E_{w}+\left(\frac{1-\gamma}{J-V}\right) J_{w}=0 \\
& \left(\frac{\gamma}{E-U}\right) E_{h}+\left(\frac{1-\gamma}{J-V}\right) J_{h}=0
\end{aligned}
$$

When these two equations are solved together to eliminate $\gamma$, it yields the contract curve in $w$ and $h$ :

$$
\frac{E_{w}}{E_{h}}=\frac{J_{w}}{J_{h}}
$$

Here the marginal rate of substitution between $w$ and $h$ is the same for the worker and the employer. This curve can be expanded by calculating $E_{h}, E_{w}, J_{h}$ and $J_{w}$ from equations (4) and (5);

$$
\frac{u_{c} \cdot h(1-\tau)}{u_{c} \cdot w(1-\tau)+u_{h}}=\frac{-h}{f^{\prime}(h)-w}
$$


As before, the left-hand side denotes the marginal rate of substitution between $w$ and $h$ for the worker, and the right-hand side denotes the marginal rate of substitution for the employer. For the specific utility function that we have assumed in equation (3), we can rewrite the contract curve in equation (16) further as:

$$
\frac{\phi(1-h) \cdot h(1-\tau)}{\phi(1-h) \cdot w(1-\tau)-[w h(1-\tau)+\bar{c}] \cdot \phi^{\prime}(1-h)}=\frac{-h}{f^{\prime}(h)-w}
$$

and solve in terms of $w$. This allows us to express the contract curve for wages as a function of hours worked:

$$
w=\frac{f^{\prime}(h) \phi(1-h)}{h \phi^{\prime}(1-h)}-\frac{\phi^{\prime}(1-h) \bar{c}}{h \phi^{\prime}(1-h)(1-\tau)}
$$

This equation yields a relationship between wages and hours worked, as is explained further in an appendix, and gives the main intuition behind the results that follow:

$$
(w h(1-\tau)+\bar{c}) \cdot \phi^{\prime}(1-h)=f^{\prime}(h) \phi(1-h)(1-\tau) .
$$

The left-hand side denotes the marginal cost of increased hours of work in utility terms and the right-hand side the marginal benefits in terms of the utility of increased output net of taxes. In order to explain the slope of the contract curve, we multiply equation (19) by $h$, which gives:

$$
\frac{f^{\prime}(h)(\phi(1-h))(1-\tau)}{(1-\tau) \phi^{\prime}(1-h)}-\frac{\bar{c}}{(1-\tau)}=w h
$$

The equation gives the relationship between hours worked and total wages. Taking the derivative of (20) with respect to $h$ gives:

$$
\frac{d(w h)}{d h}=\frac{\left(f^{\prime \prime}(h) \phi(1-h)-f^{\prime}(h) \phi^{\prime}(1-h)\right) \phi^{\prime}(1-h)+f^{\prime}(h) \phi(1-h) \phi^{\prime \prime}(1-h)}{\left(\phi^{\prime}(1-h)\right)^{2}}<0
$$

It follows that on the contract curve we have a negative relationship between total wages $w h$ and hours worked, as well as between $w$ and $h$ in equation (19). ${ }^{6}$ On a point on the contract curve, higher wages increase the marginal cost of working because they enable consumption to increase and consumption requires time. Leisure become more valuable. Only when hours of work have fallen will the marginal cost of leisure increase in the form of higher marginal productivity of hours worked.

\footnotetext{
${ }^{6}$ See also Figure A-1 in Appendix A.
} 


\subsection{The wage curve}

Equations (7), (8), (9), and (13) and the assumption of $V=0$ give a wage curve. Equation (13) becomes:

$$
\gamma\left(\frac{r+q+m(\theta) \theta}{u(c, h)-u(z(1-\tau)+\bar{c}, 0)}\right) \cdot\left(\frac{u_{c} \cdot h(1-\tau)}{r+q}\right)+\left(\frac{(1-\gamma) \cdot(r+q)}{f(h)-w h}\right)\left(\frac{-h}{r+q}\right)=0 .
$$

This equation defines an implicit function of $w$ given $h$ and $\theta$, which we can think of as a traditional wage curve. Using equation (3) and its derivative generates an explicit equation for the wage curve:

$$
w=\frac{z \cdot \phi(1)(1-\tau)+\bar{c}[1-\phi(1-h)]}{(1-\tau) h \phi(1-h)}+\frac{f(h)(1-\tau) \phi(1-h)-(z(1-\tau)+\bar{c}(1-\phi(1-h)))}{(1-\tau) h \phi(1-h)} \cdot \Psi(\theta) .
$$

The left-hand side of the equation, when multiplied by the denominator on the right-hand side, denotes the utility of after-tax wage income, while the right-hand side has the sum of the utility from receiving unemployment benefits and the extra utility of public consumption for the unemployment since the unemployed person has more time to enjoy it, on the one hand, and the share of the employed worker in the surplus generated by the match, on the other hand. The latter has the difference between two terms, where the first $f(h)(1-\tau) \phi(1-h)$ is the value of hours worked, after taxes, in terms of utility while the second is the sum of the utility of the benefits and the difference between the utility of the unemployment and the employed from public consumption. The difference between these two terms is the net utility gain from employment to be shared through bargaining between the worker and the employer. The actual weight of the employee in the bargaining is given by $0 \leq \Psi(\theta) \leq 1$, where:

$$
\Psi(\theta)=\frac{\gamma(r+q+\theta m(\theta))}{(r+q+\gamma \theta m(\theta))}
$$

The exit rate from unemployment $\theta m(\theta)$ is increasing in tightness $\theta$, and consequently $\Psi^{\prime}(\theta)>0$. When tightness increases, the unemployed has a higher exit rate from unemployment and the value of $U$ increases, and the worker fearing the prospect of unemployment less can now make more demands, thus driving the negotiated wage up. A similar reasoning gives us that $\Psi(\theta)$ is decreasing with the exit rate $q$ from employment. Finally, when $\gamma$ increases, the worker's intrinsic bargaining strength increases and the actual weight goes up. 


\subsection{A two-equation system}

The three-equation system of a wage curve, a labor demand curve, and the contract curve can be reduced further by means of several substitutions. First, by inserting the contract curve of equation (18) into the labor demand equation (11), we find a new relationship between $h$ and $\theta$, which we continue to refer to as labor demand and which is written as:

$$
\left(\frac{\phi^{\prime}(1-h) f(h)(1-\tau)-f^{\prime}(h)(1-\tau) \phi(1-h)+\bar{c} \phi^{\prime}(1-h)}{\phi^{\prime}(1-h)(1-\tau)(r+q)}\right)=\frac{a}{m(\theta)} .
$$

Second, we can insert the contract curve into the wage curve (23) and thereby obtain a new wage curve:

$$
\begin{gathered}
\frac{f^{\prime}(h) \phi(1-h)(1-\tau)-\phi^{\prime}(1-h) \bar{c}}{(1-\tau) h \phi^{\prime}(1-h)}=\frac{z \cdot(1-\tau)+\bar{c}(1-\phi(1-h))}{(1-\tau) h \phi(1-h)} \\
+\frac{f(h) \phi(1-h)(1-\tau)-z(1-\tau) \phi(1)-\bar{c}(1-\phi(1-h))}{(1-\tau) h \phi(1-h)} \cdot \Psi(\theta)
\end{gathered} .
$$

The two equations - the labor demand curve $(L D)$ and the wage curve $(W C)$ - now form a system with two unknowns, $h$ and $\theta$, which can be represented graphically.

The contract curve relation - which has a negative relationship between hours worked and wages - is built into both the labor demand curve and the wage curve and makes the $L D$ curve upward-sloping and the $W C$ curve downward-sloping in the $(\theta, h)$ space. The wage curve is downward-sloping in Figure 1 because greater labor market tightness $\theta$ makes the wage go up, as it has become easier to find a job and the higher wage raises the opportunity cost of hours worked - as is described by the equation of the contract curve - which makes negotiated hours worked go down. The labor demand curve is upward-sloping in the figure because greater labor market tightness increases the cost of posting a vacancy due to the longer expected time to fill a job. For an unchanged wage, hours worked must increase so that the value of posting a vacancy remains equal to the now higher marginal cost of posting a vacancy. ${ }^{7}$ This generates an upward-sloping relationship between hours worked and labor market tightness, as is shown in the figure. ${ }^{8}$

We now turn to the effect of raising the level of unemployment benefits $z$, having stronger labor unions, and increasing public consumption, holding the level of productivity unchanged.

\footnotetext{
${ }^{7}$ This follows from $f^{\prime}(h)>$ won the contract curve at the point of tangency of the upward-sloping isoprofit curve and the upward-sloping indifference curve, as is shown in Appendix A.

${ }^{8}$ See Appendix B on the slope of the two curves.
} 


\section{$4 \quad$ The effect of higher benefits and stronger unions}

A higher level of unemployment benefits $z$, holding taxes and public consumption unchanged, will shift the WC curve to the left, as can be seen in equation (26):

$$
0=\left(f(h)-\left(\frac{\bar{c}(1-\phi)}{\phi(1-\tau)}+\frac{z}{\phi}\right)\right) \cdot \Psi^{\prime}(\theta) d \theta+\left[\frac{1}{\phi}(1-\Psi(\theta))\right] d z
$$

We note that the sign of the first term on the right-hand side of the equation is positive because the utility of a worker who is able to keep the entirety of his output $f(h)$ net of taxes is greater than the utility of an unemployed individual,

$$
f(h)(1-\tau) \phi(1-h)+\bar{c} \phi(1-h)>\bar{c}+z(1-\tau)
$$

even though the unemployed enjoys public consumption more because he has the time to stroll in public parks! Since both terms in the parentheses are then positive in sign and so is $\Psi^{\prime}(\theta)$, higher benefits increase the utility of the unemployed, which has the effect of raising wages. This lowers the number of hours by increasing the opportunity cost of hours worked on the contract curve, making the $W C$ curve shift to the left in the figure below. As we move down the labor demand curve, fewer hours of work reduce profits and the value of a new vacancy created, which makes firms offer fewer vacancies. ${ }^{9}$ With fewer vacancies, wages will be somewhat lower and hours worked somewhat higher than they would be at unchanged wages. The net effect is to reduce both labor market tightness $\theta$ and hours worked $h$, in addition to raising the marginal productivity of hours worked due to diminishing marginal productivity.

The story here is that when unemployment benefits go up, workers must be paid higher wages because being unemployed now brings more utility. This raises the opportunity cost of working by making leisure more attractive due to a higher level of consumption, and as a result, negotiated hours of work fall. Firms' profits therefore fall (they are on the upwardsloping part of their isoprofit curves as shown in the appendix) and they post fewer vacancies.

The relative fall of $h$ and $\theta$ depends on the slope of the labor demand curve. This depends on the effect of changes in $\theta$ on the number of matches and hence the expected time before a vacancy is filled, as well as on the marginal productivity of hours worked.

\footnotetext{
${ }^{9}$ Booth and Schiantarelli (1986) explore the employment effects of a cut in hours of work in a monopoly union model with efficient bargaining and find that a reduction in hours, while keeping the number of shifts fixed, has employment effects that are ambiguous and likely to be negative for plausible parameter values.
} 
An increase in the bargaining strength of unions, $\gamma$, would have the same effect of shifting the wage curve. Taking the total differential of equation (25), and now holding $z$ fixed, gives

$$
0=\left(f(h)-\left(\frac{\bar{c}(1-\phi)}{\phi(1-\tau)}+\frac{z}{\phi}\right)\right) \Psi^{\prime}(\theta) d \theta+\left[\frac{r+q}{r+q+\gamma \theta m(\theta)}\right] d \gamma
$$

where both terms are positive. Hence the effect would be the same as that of raising benefits, in that hours worked would fall, as would the supply of vacancies.

Figure 1. Labor demand $L D$ and the wage curve $W C$ in the $(\theta, h)$ space

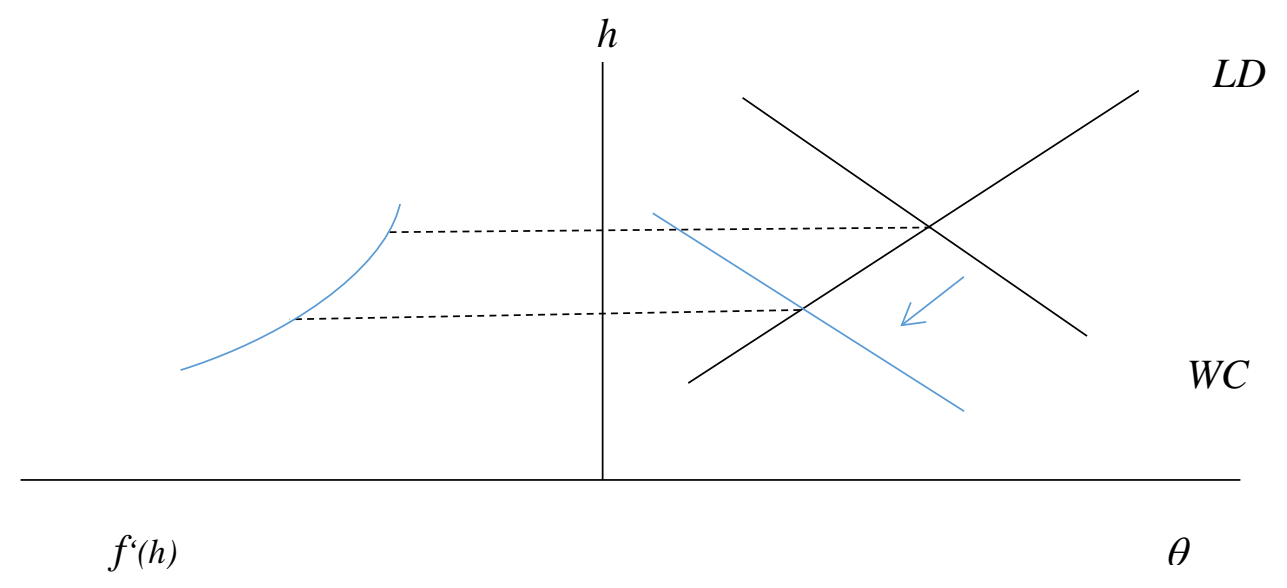

\section{The effect of increased public consumption}

Increasing public consumption also has the effect of reducing hours of work, holding taxes and benefits unchanged. Taking the total differential of the labor demand curve (25) gives

$$
\frac{1}{(1-\tau)(r+q)} d \bar{c}=-\frac{m^{\prime}(\theta) a}{(m(\theta))^{2}} d \theta \text {. }
$$

Here both sides of the equation are positive, so that the $L D$ curve shifts to the right in the figure below. Intuitively, a higher level of public consumption reduces the negotiated wage on the contract curve, holding hours worked unchanged, as seen in equation (18). Alternatively, hours worked fall for a given wage. Taking the total differential of the wage curve (26) gives

$$
\frac{-1}{(1-\tau)} d \bar{c}=\frac{(\phi(1)-\phi(1-h))}{(1-\tau) \phi(1-h)}(1-\Psi(\theta)) d \bar{c}+\left(f(h)-\left(\frac{\bar{c}(1-\phi)}{\phi(1-\tau)}+\frac{z}{\phi}\right)\right) \Psi^{\prime}(\theta) d \theta
$$


Since both terms on the right-hand side of the equation are positive - see equation (28) above - the WC curve shifts to the left in the figure. Intuitively, the higher level of public consumption has the effect of increasing the opportunity cost of working - think of beautiful public parks pulling you from the office! - making hours worked fall. There is also the indirect effect that higher levels of public consumption benefit the unemployed more, since they have more time to enjoy it, which then raises the negotiated wage, due to the employed workers' improved fallback position, and hence also the opportunity cost of hours worked.

The two shifts make the curves intersect at a lower level of hours worked $h$ while the effect on labor market tightness $\theta$ is ambiguous, as is shown in the figure below. The following section has numerical simulations that show that $\theta$ will fall and unemployment will rise given plausible parameter values.

Figure 2. Labor demand $L D$ and the wage curve $W C$ in the $(\theta, h)$ space

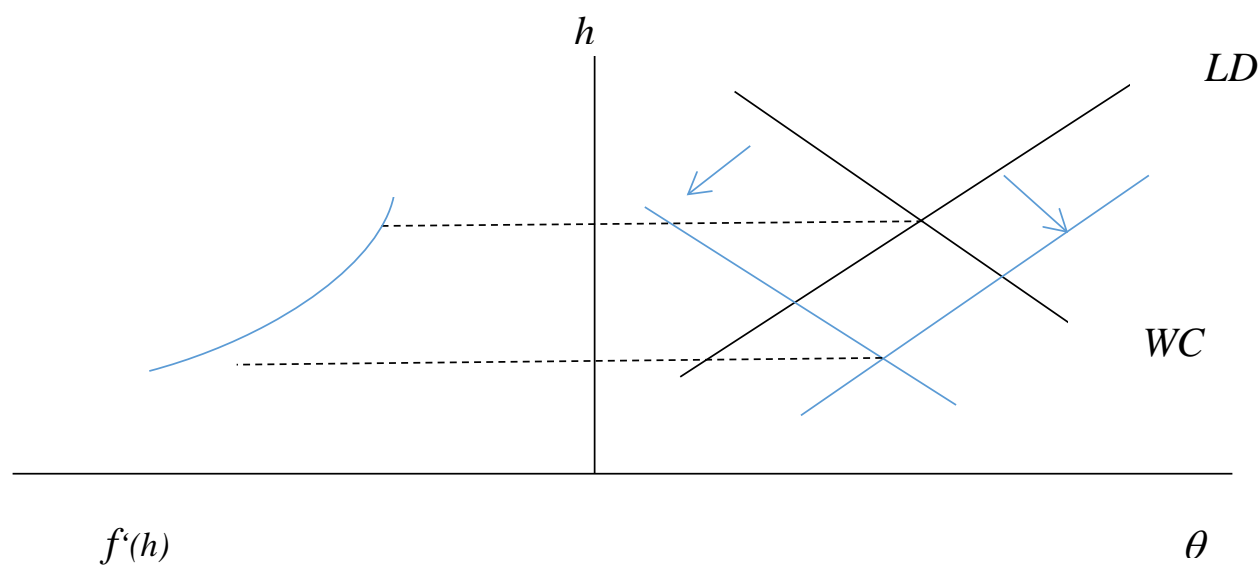

\section{Taxes}

We finally come to the effect of higher taxes holding benefits and public consumption unchanged. To start with, taxes are neutral in the absence of public consumption, as is seen from the two equations below. Starting with the $L D$ curve, we find the total differential, which describes the effect of higher taxes on labor market tightness:

$$
\frac{\bar{c}}{(1-\tau)^{2}(r+q)} d \tau=-\frac{m^{\prime}(\theta) a}{(m(\theta))^{2}} d \theta
$$

Here both sides of the equation are positive as long as $\bar{c}>0$, which makes the $L D$ curve shift to the right in the figure above. The reason is similar to the one for the shift of the $L D$ curve 
following an increase of public consumption. The higher taxes have the effect of lowering the wage for a given number of hours worked along the contract curve, which makes firms offer more vacancies.

Turning to the wage curve, we find the following differential:

$$
\frac{-\bar{c} \phi}{(1-\tau) \phi^{\prime}} d \tau=\frac{\bar{c}(1-\phi)}{(1-\tau)^{2} \phi}(1-\Psi(\theta)) d \tau+\left(f(h)-\left(\frac{\bar{c}(1-\phi)}{\phi(1-\tau)}+\frac{z}{\phi}\right)\right) \Psi^{\prime}(\theta) d \theta
$$

In this case, the left-hand side of the equation is negative while the right-hand side is positive. As a result, the $W C$ curve shifts to the left in the figure. Again, the effect depends on $\bar{c}>0$. The two shifts are thus of the same sign as those shown for the effect of increased public consumption. Tax increases therefore have the effect of reducing hours of work, as did higher benefits and a higher level of public consumption. The effect on labor market tightness is ambiguous. The following section has numerical simulations that show that $\theta$ will fall and unemployment will rise given plausible parameter values.

\section{Simulations}

We have found that both higher levels of public consumption and higher taxes have the effect of reducing the number of hours of work while having a theoretically ambiguous effect on labor market tightness, $\theta$, and hence the rate of unemployment in steady state. In order to resolve the ambiguity, we perform numerical simulations for a balanced-budget increase in tax rates and public consumption. The parameter values are chosen to resemble a typical Continental European country. ${ }^{10}$

\footnotetext{
${ }^{10}$ The real rate of interest is calculated as the average of the difference between the nominal interest rate on 10year German government bonds and German inflation between 2001 and 2008. The unemployment benefits replacement rate is the German number for year 1999 in Nickel et al. (2005) (37\% of average wages, wh). The quit rate is set at 7.5\%, as in Germany for 1983-1990, and the population growth rate is set at $0 \%$ to fit recent experience. Finally, hiring costs are adjusted so as to generate an unemployed rate close to the observed one.
} 
Figure 3. The effect of higher taxes and public consumption on hours and unemployment
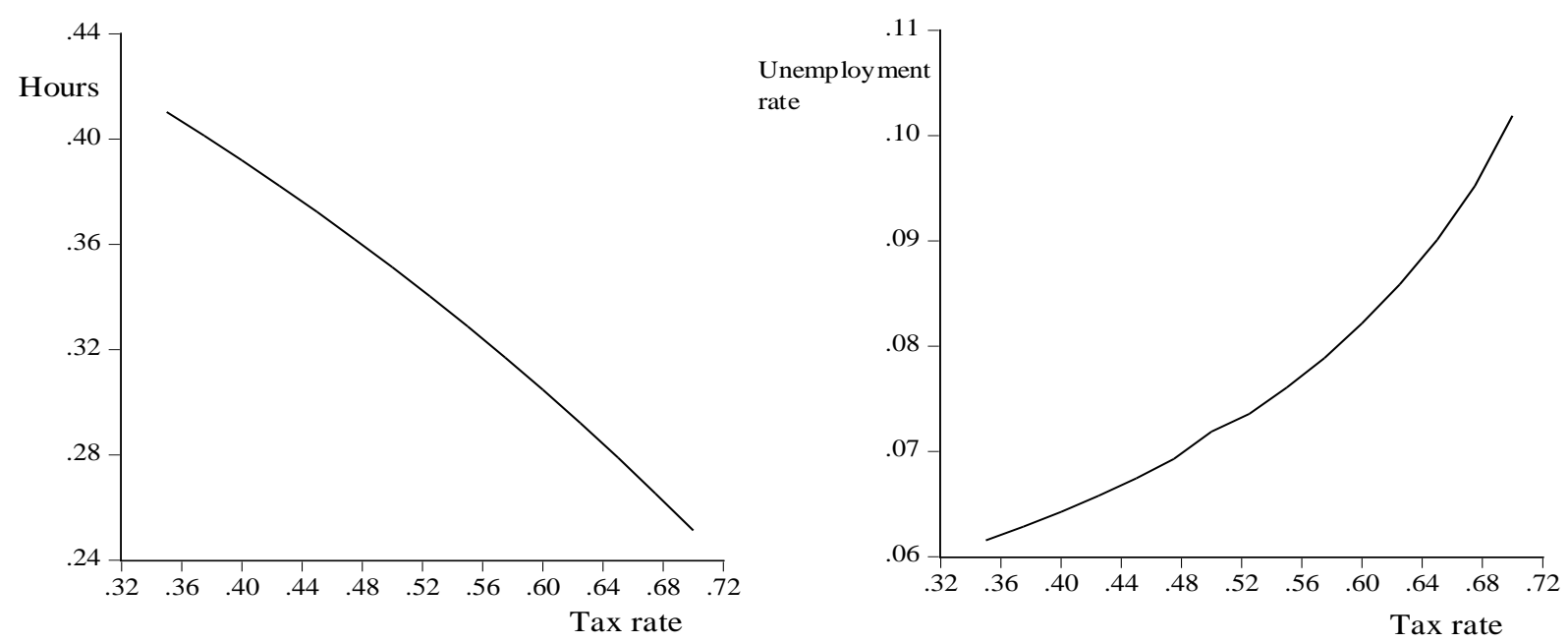

Parameter values: $z=0.21 h i=0.18, q=0.075, r=0.024, n=0.0, \gamma=0.50, f(h)=h^{0.5}, \phi(1-h)=(1-h)^{0.5}$.

The simulations show that raising tax rates from $35 \%$ to $70 \%$ and spending the increased tax receipts on public consumption would lower the number of hours of work per week from 41.6 to 25.9 and increase the rate of unemployment from $8.8 \%$ to $14.1 \%$. Thus the downward shift of the WC curve in Figure 2 is much more pronounced than the downward shift of the $L D$ curve.

\section{The data}

Our model has the empirical prediction that higher non-wage income -in the form of either unemployment benefits or public consumption - as well as stronger labor unions will have the effect of both reducing the number of hours worked for employed workers and increasing the rate of unemployment. It follows that countries where such non-wage income is high should have shorter work weeks as well as higher unemployment rates, other things being equal. All three variables increased in the large European Continental economies in the 1970s and the 1980s. Thus public consumption increased on the Continent where hours of work fell in the 1970 and 1980s but fell in the U.S. and stayed roughly constant in the U.K. A similar pattern emerges for union density. ${ }^{11}$

\footnotetext{
${ }^{11}$ Public consumption in the U.S. was $18.1 \%$ of GDP in $1970,15.9 \%$ in 1980 and $14.0 \%$ in 2000 . In the United Kingdom public consumption went from $18.3 \%$ in 1970 to $21.9 \%$ in 1980 to $18.3 \%$ in 2000 . In contrast public consumption in France went from $17.3 \%$ of GDP in 1970 to $21.4 \%$ in 1980 to $22.9 \%$ in 2000. In Italy the comparable numbers were $15.4 \%$ in $1970,16.9 \%$ in 1980 , and 18.3 in 2000 . In Spain we go from $10.1 \%$ in 1970 to $13.9 \%$ in 1980 to $17.1 \%$ in 2000 . Union density was $24.7 \%$ in Italy in $1960,37.0 \%$ in $1970,49.6 \%$ in 1980
} 
In order to explore the empirical validity of our model, we explore cross-sectional data for twenty OECD countries. We use a matrix of six variables: public consumption as a share of GDP, the compensation of government employees as a share of GDP, social benefits as a share of GDP, union density, weekly hours worked, and the rate of unemployment. ${ }^{12} \mathrm{We}$ summarize the information in it by calculating a set of principal components. We take the $(20 * 6)$ matrix $X$ of these six variables for twenty OECD countries for the year $2005,{ }^{13}$ shown in Table C-1 in the appendix, and diagonalize its covariance matrix $X^{\prime} X$

$$
A^{\prime} X^{\prime} X A=\Phi
$$

where $\underline{A}$ is the matrix of orthogonal eigenvectors and $\Phi$ is the $(6 * 6)$ diagonal matrix of eigenvalues. We can then define $Z=X A$ to be the $(20 * 6)$ matrix of principal components (PCs), with each column of $Z$ being a $(20 * 1)$ vector of observations for one principal component. Each eigenvalue then shows the proportion of the total variance of matrix $X$ explained by the relevant PC. Table 1 below gives the four largest eigenvalues and the percentage of the variance and the cumulative percentage of the variance of matrix $X$ explained by the principal components.

Table 1. Principal components

\begin{tabular}{lccc}
\hline Number & Eigenvalues & $\begin{array}{c}\text { Percentage } \\
\text { of variance } \\
\text { explained }\end{array}$ & $\begin{array}{c}\text { Cumulative } \\
\text { percentage } \\
\text { explained }\end{array}$ \\
\hline First principal component & 3.34 & 0.56 & 0.56 \\
Second principal componen & 1.22 & 0.20 & 0.76 \\
Third principal component & 0.55 & 0.09 & 0.85 \\
Fourth principal component & 0.49 & 0.08 & 0.93 \\
\hline
\end{tabular}

The first PC explains $56 \%$ of the variation in the data and the second $20 \%$ of the variation. The factor loading corresponding to each of the principal components is shown in the table below, which has the eigenvectors corresponding to each PC.

and, 34.8\% in 2000 In contrast, density was 30.9\% in the U.S. in 1960, 27.4\% in 1970, 22.1\% in 1980 and $12.9 \%$ in 2000. Density in the U.K. fell from 38.8\% in 1960 to 30.2\% in 2000. Source: OECD statistics (www.oecd.org).

${ }^{12}$ See definition of variables in Table C-2 in Appendix C.

${ }^{13}$ The countries are Australia, Austria, Belgium, Canada, Denmark, Finland, France, Germany, Greece, Ireland, Italy, Japan, the Netherlands, New Zealand, Norway, Portugal, Spain, Sweden, the UK, and the US. 
Table 2. Eigenvectors for principal components

\begin{tabular}{lcccc}
\hline Variables & PC 1 & PC 2 & PC 3 & PC 4 \\
\hline Public consumption & 0.49 & -0.07 & -0.28 & 0.43 \\
Social spending (\% & 0.44 & 0.35 & -0.07 & 0.53 \\
$\begin{array}{l}\text { Compensation of } \\
\text { government }\end{array}$ & 0.48 & -0.07 & 0.20 & -0.30 \\
Union density (per & 0.37 & -0.44 & 0.69 & 0.00 \\
$\begin{array}{l}\text { Unemployment rate } \\
\text { (per cent of civilian }\end{array}$ & 0.15 & 0.81 & 0.33 & -0.30 \\
Weekly hours & -0.43 & 0.10 & 0.54 & 0.59 \\
\hline
\end{tabular}

The loading for the first PC is positive for public consumption, social spending, the compensation of government employees, and union density, and then negative for hours worked and positive for unemployment. This is in accordance with the model set out in this paper. We note, however, that the factor loading for unemployment is smaller than for weekly hours worked. The second PC appears to capture the relationship between social spending and unemployment.

\section{Conclusions}

We have shown that a shorter work week and higher unemployment rates observed in many European economies may have a unified cause in a higher level of benefits and public consumption relative to productivity and greater power of labor unions. ${ }^{14}$

In our model, when workers are paid more for being idle, employed workers manage through bargaining to obtain a higher wage, which raises the opportunity cost of working due to greater consumption opportunities without raising the attractions of work through higher productivity. The higher the wage, the greater are the opportunities to travel or enjoy consumption at home, which requires more leisure time. Firms respond to the higher wages and lower number of hours by reducing the number of vacancies, and we end up with both higher unemployment and a shorter work week. More powerful unions will also raise the wage paid per hour, with the same effect on hours of work and unemployment.

The model encompasses several of the proposed explanations for fewer hours of work mentioned at the beginning of this paper. Thus the model explains why Europeans may have a

\footnotetext{
${ }^{14}$ The negative effect of government expenditures on labor input and hence output is what Knoester (1991) has called the inverted Haavelmo effect - increased spending by the government makes employment and hours worked fall, contrary to Keynesian predictions.
} 
greater preference for leisure than Americans, as is proposed by Blanchard (2004). The model explains why lower hours are correlated with unionization and labor market rigidities such as unemployment benefits, as is shown by Alesina et al. (2006). The model can be viewed as complementary to the Bell and Freeman (2001) thesis; i.e., that it is the unequal distribution of income that drives Americans to work more than Europeans. It is also consistent with the finding by Bell and Freeman (1995) that, in spite of fewer hours of work, German workers desire to reduce their time at work while Americans want to increase it. 


\section{References}

Alesina, Alberto F., Edward L. Glaeser, and Bruce Sacerdote (2006), "Work and Leisure in the U.S. and Europe: Whey So Different?”, NBER Macroeconomics Annual. MIT Press.

Becker, Gary (1965), “A Theory of the Allocation of Time,” The Economic Journal, 75 (299), 493-517.

Bell, Linda A. and Richard B. Freeman (1995), "Why do Americans and Germans Work Different Hours?” in F. Buttler, W. Franz, R. Schettkat and D. Soskice (Eds.), Institutional Frameworks and Labor Market performance. Routledge Press, London.

Bell, Linda A. and Richard B. Freeman (2001), “The Incentive for Working Hard: Explaining Hours Worked Differences in the US and Germany,” Labour Economics, 8, 181-202.

Blanchard, Olivier (2004), “The Economic Future of Europe,” NBER Working Paper,” 10310.

Blanchard, Olivier and Justin Wolfers (2000). "The Role of Shocks and Institutions in the Rise of European Unemployment: the Aggregate Evidence,” The Economic Journal, 110 (462), 1-33.

Booth, Alison and F. Schiantarelli (1986), "Employment Effects of a Shorter Work Week,” Economica, 54, 237-48.

Cahuc, Pierre and André Zylberberg (2004), Labor Economics, The MIT Press.

Fitoussi, Jean-Paul, David Jestaz, Edmund S. Phelps, and Gylfi Zoega (2000), "Roots of the Recent Recoveries: Labor Reforms or Private Sector Forces,” Brookings Papers on Economic Activity, 1, 237-311.

Glaeser, Edward L., Bruce I. Sacerdote, and Jose A. Scheinkman (2003), “The Social Multiplier,” Journal of the European Economic Association, 1 (2-3), 345-353.

Hall, Axel and Gylfi Zoega (2014). Values and Labor Force Participation in the Nordic Countries. Economics: The Open-Access, Open-Assessment E-Journal, 8 (2014-41): 1—43

Hoon, Hian Teck and Edmund S. Phelps (1997), "Growth, Wealth and the Natural Rate: Is Europe’s Crisis a Growth Crisis?” European Economic Review, 41 (3-5), 549-557.

Hunt, Jennifer and Lawrence F. Katz (1999), "Hours Reductions as Work-Sharing,” Brookings Papers on Economics Activity 1.

Knoester, Anthony (1991), “The Inverted Haavelmo Effect and the Economic Consequences of Fiscal Policies in the 1970s and 1980s,” Research Memorandum 9103, University of Nijmegen.

Layard, Richard., Stephen Nickell, and Richard Jackman (2005), Unemployment: Macroeconomic Performance and the Labour Market, Oxford University Press. 
Marshall, Alfred (1890), Principles of Economics, Macmillan and Co., Limited, London.

Mortensen, Dale T. and Christopher A. Pissarides (1994), "Job Creation and Job Destruction in the Theory of Unemployment," Review of Economic Studies, 61, 397-415.

Ngai, L. Rachel and Christopher A. Pissarides (2007), “Trends in Hours and Economic Growth,” Review of Economic Dynamics, 11, 239-256.

Nickell, Stephen, Luca Nunziata and Wolfgang Ochel (2005), "Unemployment in the OECD since the 1960s: What do we know?” The Economic Journal, 115, 1-27.

Phelps, Edmund S. (1994), Structural Slumps: The Modern Equilibrium Theory of Unemployment, Interest, and Assets, Harvard University Press.

Phelps, Edmund S. and Gylfi Zoega (2001), “Structural Booms,” Economic Policy, 16 (32), 85-136.

Pissarides, Christopher A. (1985), "Short-Run Dynamics of Unemployment, Vacancies, and Real Wages,” American Economic Review, 75, 676-690.

Pissarides, Christopher A. (2000), Equilibrium Unemployment Theory, 2d ed. Cambridge, MA: MIT Press.

Pissarides, Christopher A. (2007), "Unemployment and Hours of Work: The North Atlantic Divide Revisited,” International Economic Review, 48 (1), 1-36.

Prescott, Edward C. (2004), "Why Do Americans Work So Much More than Europeans?” Federal Reserve Bank of Minneapolis Quarterly Review, 28 (1), 2-13.

Rogerson, Richard (2006), “Understanding Differences in Hours Worked,” Review of Economic Dynamics, 9, 365-409.

Scitovsky, Tibor (1951), Welfare and Competition: The Economcis of a Fully Employed Economy, Chicago.

Winston, Gordon (1965), “Taxes, Leisure and Public Goods,” Economica, 32, 65-69.

Zoega, Gylfi (1997), “Public Consumption and Unemployment,” Scottish Journal of Political Economy, 44 (3), 269-279. 


\section{Appendix A: Derivation of the contract curve}

It is possible to draw the tangency between the isoprofit and indifference curves as a solution to the contract curve in $(w, h)$-space.

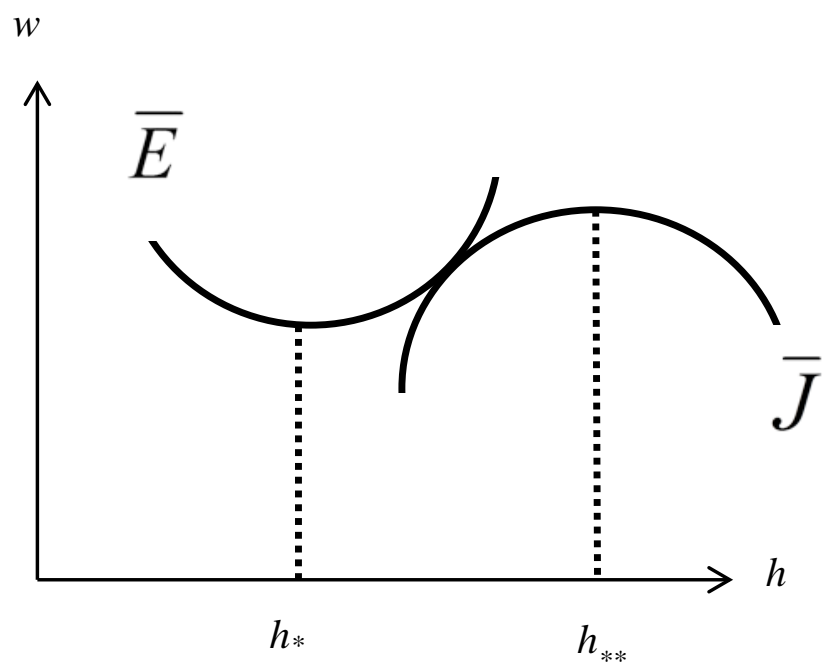

Figure A-1. Contract curve, isoprofit curve and indifference curve

The slope of the indifference curve is given by:

$$
\frac{d w}{d h}=-\frac{E_{h}}{E_{w}}=-\frac{u_{c} w(1-\tau)+u_{h}}{u_{c} h(1-\tau)}=-\frac{1}{h(1-\tau)}\left(w(1-\tau)+\frac{u_{h}}{u_{c}}\right)
$$

For the neoclassical model of consumption-labor choice the worker takes $w$ as given and maximizes utility so that the slope of the budget constraint is equal to marginal rate of substitution between work and consumption. The slope of the budget constraint in that case is $w(1-\tau)$, and $-u_{h} / u_{c}$ is the marginal rate of substitution between work and consumption, the rate at which the consumer demands one more unit of consumption for an hour's increase in work (positive here). In this case, $d w / d h$ is zero.

Here both hours worked and wages are the result of a bargaining process between the firm and the worker. If $h_{*}$ is the tangency point that has been described here, and if $h<h_{*}$, the slope of budget constraint is greater than the marginal rate of substitution and $d w / d h$ will be negative. The opposite applies when $h>h_{*}$. Thus the $\bar{E}$ curve is downward-sloping to the left of $h^{*}$ and upward-sloping to the right of $h^{*}$. Since both $h$ and $w$ are determined in the bargaining, $h$ does not have to equal $h^{*}$ in equilibrium.

To see how the indifference curve $\bar{E}$ shifts, we look at:

$$
d E=E_{w} d w+E_{h} d h
$$


For an increase in $w$ for a fixed $h, E$ will increase as $E_{w}$ is positive. Hence an upward shift in the indifference curve represents a level of utility for the worker. This can also be seen if we look at an increase in $h$ for a fixed $w$. This, however, is a bit more complicated. From equation (4), we get:

$$
E_{h}=\frac{u_{c} \cdot w(1-\tau)+u_{h}}{r+q}=\frac{u_{c}}{r+q}\left(w(1-\tau)+\frac{u_{h}}{u_{c}}\right)
$$

From earlier discussion, we know that if $h<h_{*}$, then $E_{h}>0$, and for an increase in $h, E$ increases. The opposite applies if $h>h_{*}$.

The slope of the isoprofit curve is given by:

$$
\frac{d w}{d h}=-\frac{J_{h}}{J_{w}}=\frac{f^{\prime}(h)-w}{h}
$$

The isoprofit curve is upward-sloping while marginal product is higher than the wage and is downward-sloping when marginal product has become lower than the wage. For higher profits, the isoprofit curve will shift downwards.

The same logic applies here as is discussed earlier, in that the firm does not set marginal product equal to the wage rate because of the bargain between the firm and the worker. Let $h^{* *}$ be a point on the isoprofit curve where the wage is equal to the marginal product. When $h<h^{* *}$, the marginal product is greater than the wage. Conversely, when $h>h^{* *}$, the opposite applies.

To see how the isoprofit curve $\overline{\boldsymbol{J}}$ shifts, we look at:

$$
d J=J_{w} d w+J_{h} d h
$$

For an increase in $w$ for a fixed $h, J$ will decrease as $J_{w}$ is negative. Hence a downward shift in the isoprofit curve represents a higher profit for the firm. This can also be seen if we look at an increase in $h$ for a fixed $w$. This, again, is a bit more complicated. From equation (7) we get:

$$
J_{h}=\frac{f^{\prime}(h)-w}{r+q}
$$

From earlier discussion, we know that if $h<h_{* *}$, then $J_{h}>0$, and for an increase in $h, J$ increases. The opposite applies if $h>h_{* *}$.

The only thing that is left to determine is the location of the point of tangency between the indifference curve and the isosprofit curve. If the point of tangency for a given indifference 
curve is below $h^{*}$, it will be on the downward-sloping part on the indifference curve and the downward-sloping part of the isoprofit curve, in which case the contract curve will be upward-sloping. If the tangency point is for a given indifference curve above ${ }^{*}$, the opposite will be the case: the point of tangency will be on the upward-sloping part of the indifference curve and the upward-sloping part of the isoprofit curve.

Setting the slope of the indifference curve equal to the slope of the isoprofit curve gives:

$$
f^{\prime}(h)-w=-\frac{1}{(1-\tau)}\left(w(1-\tau)+\frac{u_{h}}{u_{c}}\right)
$$

In equilibrium, the marginal product of labor must be strictly greater than the wage rate because firms must be compensated for their hiring costs. Hence equation (A-7) implies that when hours are set after Nash bargain, we have

$$
\left(w(1-\tau)+\frac{u_{h}}{u_{c}}\right)<0
$$

Using the utility function given by equation (3) yields:

$$
w(1-\tau)<\frac{c \cdot \phi^{\prime}(1-h)}{\phi(1-h)}
$$

which indicates that the marginal rate of substitution between consumption and hours worked is greater than the wage, so hours worked are now higher than is implied by the worker's choice rule of no bargaining.

The difference between hours worked here and in the no-bargaining solution originates in the hiring costs hi, which is the cost of maintaining a vacant position. In the absence of bargaining, workers choose their number of hours worked by comparing the marginal cost of working (loss of leisure) with the marginal benefit of after-tax wage income. In the Nash bargaining, the costs and benefits to the firm must also be taken into account. The joint marginal cost of one more hour to the firm and the worker is still the loss of leisure to the worker, but the joint gain is the after-tax product from one more hour. The bargaining solution gives the same result as in a competitive framework, when wages are given only when the wage rate is equal to the marginal product. This cannot happen in equilibrium due to the hiring costs hi faced by firms, which drive a wedge between marginal product and wages.

Equation (A-7) with the utility function in equation (3) gives:

$$
f^{\prime}(h)-w=-\frac{1}{(1-\tau)}\left(w(1-\tau)-\frac{c \cdot \phi^{\prime}(1-h)}{\phi(1-h)}\right)
$$


and because wages cancel out on both sides, we get:

$$
f^{\prime}(h)=\frac{c \cdot \phi^{\prime}(1-h)}{(1-\tau) \phi(1-h)}
$$

This equation states that on the contract curve, the after-tax marginal product in utility terms should be equal to marginal disutility of one more hour worked.

Inserting consumption from the budget constraint in equation (1) facing the worker into equation (A-11) gives equation (18), the point of tangency on the contract curve that has been shown to have a negative slope since both the indifference curve and the isoprofit curves are upward-sloping at the point of tangency. Mathematically, however, $d w / d h$ cannot be determined from equation (18). As is shown in equation (21), $d(w h) / d h<0$ and as:

$$
\frac{d(w h)}{d h}=\frac{d w}{d h} h+w<0
$$

The contract curve has a negative slope, as is shown in Figure A-1. At each point on the contract curve, workers work more hours than they would in the absence of bargaining and firms accept fewer hours of work from each worker than they would have chosen in the absence of bargaining with a given wage.

\section{Appendix B: Slope of labor demand and wage curve}

Taking the total differential of the labor demand curve in equation (25) above gives:

$$
\left(\frac{f^{\prime}}{(r+q)}-\frac{\left(f^{\prime \prime} \phi-f^{\prime} \phi\right) \phi^{\prime}(r+q)+\phi^{\prime \prime} f^{\prime} \phi^{\prime}(r+q)}{\left(\phi^{\prime}(r+q)\right)^{2}}\right) d h=\left(-\frac{m^{\prime}(\theta) a}{(m(\theta))^{2}}\right) d \theta
$$

We see from this that the labor demand curve is upward-sloping since each parenthesis is positive. ${ }^{15}$ Doing the same for the wage curve from equation (26) and using the results of equation (21) gives:

$$
\begin{aligned}
& \frac{d(w h)}{d h} d h=\left[\left(\frac{\bar{c} \phi^{\prime}}{\phi^{2}(1-\tau)}+\frac{z \phi^{\prime}}{\phi^{2}}\right)+\left(f^{\prime}(h)-\left(\frac{\bar{c} \phi^{\prime}}{\phi^{2}(1-\tau)}+\frac{z \phi^{\prime}}{\phi^{2}}\right)\right) \Psi(\theta)\right] d h \\
& +\Psi^{\prime}(\theta) d \theta
\end{aligned}
$$

From this we see that the wage curve is downward-sloping because the term on the left-hand side is negative from equation (21), while the two terms on the right-hand side are positive.

\footnotetext{
${ }^{15}$ Assuming that $f^{\prime \prime}<0$.
} 


\section{Appendix C: The data and their sources}

Table C-1. The data

\begin{tabular}{lcccc|cc}
\hline Country & $\begin{array}{c}\text { Public } \\
\text { consumption }\end{array}$ & $\begin{array}{c}\text { Compens. } \\
\text { employees }\end{array}$ & $\begin{array}{c}\text { Social } \\
\text { benefits }\end{array}$ & $\begin{array}{c}\text { Union } \\
\text { density }\end{array}$ & $\begin{array}{c}\text { Hours } \\
\text { worked }\end{array}$ & $\begin{array}{c}\text { Unemp. } \\
\text { rate }\end{array}$ \\
\hline Australia & $\%$ & $\%$ & $\%$ & $\%$ & hours & $\%$ \\
Austria & 0.17 & 0.08 & 0.08 & 22.29 & 42.74 & 5.00 \\
Belgium & 0.19 & 0.09 & 0.24 & 33.32 & 41.75 & 5.20 \\
Canada & 0.23 & 0.12 & 0.23 & 53.68 & 38.91 & 8.40 \\
Denmark & 0.19 & 0.12 & 0.08 & 27.73 &.. & 6.80 \\
Finland & 0.26 & 0.17 & 0.18 & 70.67 & 38.93 & 4.80 \\
France & 0.22 & 0.14 & 0.19 & 70.65 & 39.48 & 8.40 \\
Germany & 0.24 & 0.13 & 0.23 & 7.67 & 39.05 & 8.30 \\
Greece & 0.19 & 0.08 & 0.27 & 21.68 & 39.70 & 11.20 \\
Ireland & 0.17 & 0.11 & 0.16 & 24.64 & 41.61 & 9.60 \\
Italy & 0.14 & 0.10 & 0.11 & 33.96 & 39.79 & 4.80 \\
Japan & 0.20 & 0.11 & 0.20 & 33.59 & 40.05 & 7.80 \\
Netherlands & 0.18 & 0.06 & 0.11 & 18.80 &.. & 4.40 \\
New Zealand & 0.24 & 0.10 & 0.19 & 20.56 & 37.63 & 4.70 \\
Norway & 0.17 & 0.02 & 0.09 & 20.85 & 43.27 & 3.80 \\
Portugal & 0.20 & 0.12 & 0.15 & 54.89 & 38.22 & 4.60 \\
Spain & 0.21 & 0.14 & 0.18 & 21.25 & 40.17 & 7.70 \\
Sweden & 0.18 & 0.10 & 0.14 & 14.83 & 40.86 & 9.20 \\
United Kingdom & 0.26 & 0.15 & 0.20 & 76.52 & 38.73 & 7.80 \\
United States & 0.21 & 0.11 & 0.13 & 28.42 & 42.36 & 4.70 \\
\hline & 0.16 & 0.03 & 0.09 & 11.96 & 41.63 & 5.10 \\
\hline
\end{tabular}


Table C-2. Variables and their sources

\begin{tabular}{|c|c|c|}
\hline Variable & Definition & Source \\
\hline Union density & $\begin{array}{l}\text { Ratio of wage and salary } \\
\text { earners that are trade union members } \\
\text { and the total number of wage } \\
\text { and salary earners. }\end{array}$ & $\begin{array}{l}\text { OECD } \\
\text { (www.oecd.org) }\end{array}$ \\
\hline $\begin{array}{l}\text { Public } \\
\text { consumption }\end{array}$ & $\begin{array}{l}\text { Public consumption as a share of GDP, } \\
2005 .\end{array}$ & $\begin{array}{l}\text { IMF } \\
\text { (International } \\
\text { Financial } \\
\text { Statistics) }\end{array}$ \\
\hline $\begin{array}{l}\text { Compensation of } \\
\text { government } \\
\text { employees. }\end{array}$ & $\begin{array}{l}\text { Compensation of government employees } \\
\text { as share of GDP, general government, } \\
2005 .\end{array}$ & $\begin{array}{l}\text { IMF } \\
\text { (International } \\
\text { Financial } \\
\text { Statistics) } \\
\end{array}$ \\
\hline Social spending. & $\begin{array}{l}\text { Social Expenditures - Aggregated data } \\
\% \text { of GDP. }\end{array}$ & $\begin{array}{l}\text { IMF } \\
\text { (International } \\
\text { Financial } \\
\text { Statistics) }\end{array}$ \\
\hline $\begin{array}{l}\text { Unemployment } \\
\text { rate. }\end{array}$ & $\begin{array}{l}\text { Unemployment as a share of the civilian } \\
\text { labor force. }\end{array}$ & $\begin{array}{l}\text { OECD } \\
\text { (www.oecd.org) }\end{array}$ \\
\hline Hours worked. & $\begin{array}{l}\text { Hours worked, dependent employees, } \\
\text { full-time, all workers. }\end{array}$ & $\begin{array}{l}\text { OECD } \\
\text { (www.oecd.org) }\end{array}$ \\
\hline
\end{tabular}

